\title{
Association of House Fly (Musca domsestica) Intensity by Spot Card and Manure Moisture in Caged Layer Houses
}

\author{
N. Sathiyamoorthy*, K. Senthilvel, N. Rani, K. Ramya and G. Ponnudurai \\ Department of Veterinary Parasitology, Veterinary College and Research Institute, \\ Namakkal- 637 001, Tamil Nadu, India \\ *Corresponding author
}

\section{A B S T R A C T}

\begin{tabular}{|l|}
\hline Ke y w o r d s \\
Houseflies, Spot card, \\
$\begin{array}{l}\text { Manure moisture, } \\
\text { Namakkal district, } \\
\text { Tamil Nadu }\end{array}$ \\
\hline Article Info \\
\hline $\begin{array}{l}\text { Accepted: } \\
\text { 24 January 2018 } \\
\text { Available Online: } \\
\text { 10 February 2018 }\end{array}$ \\
\hline
\end{tabular}

House fly intensity at five different poultry farms in Namakkal region of Tamil Nadu was monitored by spot cards. A plain white sheet of $12.5 \times 7.5 \mathrm{~cm}$ square was pinned to thermocole of similar size and tied to cages above two feet from the floor in narrow caged poultry houses and three feet above from the floor in high rise caged poultry houses. After 24 hours, the spot cards were removed and the regurgitation and faecal spots made by adult flies were counted. The mean number of fly specks per card was $59 \pm 8$ in farm-I, $195 \pm 28$ in farm-II, $63 \pm 12$ in farm-III, $34 \pm 5$ in farm-IV and $101 \pm 19$ in farm-V. About $50 \mathrm{gms}$ of manure collected in different points of selected farms were pooled and moisture estimation was carried out by oven drying method. The moisture content of manure was 67.49, 86.32, 48.64, 41.56 and 79.11 per cent in farm-I, farm-II, farm-III, farm-IV and farm-V respectively. Higher fly population was observed in farms (I, II and V) that had manure moisture content $>60$ per cent and mild to moderate level was noticed in farms (III and IV) with moisture level ranged between 40 and 50 per cent.

\section{Introduction}

House fly, Musca domestica is one of the important insect pests in caged layer houses (Axtell and Arends, 1990). In poultry farms, great quantities of manure exposed to high temperature and humidity levels provide an ideal environment for the development of house fly.

High density of flies can cause stress to poultry workers and hens and also affect the economic value of their products (Learmount et al., 2002). The aim of the present work was to study the correlation of house fly intensity by spot card and manure moisture in caged layer poultry houses in Namakkal district.

\section{Materials and Methods}

\section{Spot card method}

The fly intensity was estimated in different five poultry farms by using the spot card technique. A plain white sheet of $12.5 \times 7.5 \mathrm{~cm}$ square was pinned to thermocole of similar size and tied to cages above two feet from the floor in narrow caged poultry houses (FarmII and V) and three feet above from the floor in high rise caged poultry houses (Farm-I, III 
and IV). After 24 hours, the spot cards were removed and the regurgitation and faecal spots made by adult flies were counted. Ten spot cards were placed in each poultry farm and the average of fly specks was calculated as spot card index.

The fly intensity in this study was graded with some modification as reported by Rutz and Pitts (1993) and the intensity in which fly specks, < 50 Low; 51 to 100 - Moderate; 101 to 200- High and Above 200 - Very high.

\section{Manure moisture estimation}

About 50 gms of manure collected in different points of selected farms were pooled and moisture estimation was carried out by oven drying method (Reeb and Milota, 1999).

\section{Results and Discussion}

\section{Spot card methods}

The mean number of fly specks per card was $59 \pm 8$ in farm-I, $195 \pm 28$ in farm-II, $63 \pm 12$ in farm-III, $34 \pm 5$ in farm-IV and $101 \pm 19$ in farm-V. Out of five farms examined, the fly intensity was higher in farms II and $\mathrm{V}$, moderate in farms I and III and lower in farmIV.

The data obtained in the spot card indices in the present study indicated that house fly populations were higher in farms II and V (narrow cage system), moderate in farms I and III and lower in farm IV. The higher fly intensity in narrow caged poultry farms could be due to poor sanitation of the farm with improper management of manure.

This finding confirms the observations of Quisenberry and Foster (1984) and Tamilam (2008), who observed varying fly population depends on the type of houses and stated that sanitation had a direct effect on fly numbers.

\section{Manure moisture estimation}

Fifty grams of manure in each farm was collected and the moisture level was estimated by oven drying method. The moisture content of manure was 67.49, 86.32, 48.64, 41.56 and 79.11 per cent in farm-I, farm-II, farm-III, farm-IV and farm-V respectively.

Higher fly population was observed in farms (I, II and V) that had manure moisture content $>60$ per cent and mild to moderate level was noticed in farms (III and IV) with moisture level ranged between 40 and 50 per cent.

The fly populations in farms can be well correlated with moisture content of manure in the present study. Higher fly production was observed in farms that had manure moisture content $>60$ per cent.

According to Barth (1986), litter management in poultry farms played an important role to keep the fly populations below the threshold level and if the moisture level above 60 per cent, the fly population reaches to the nuisance level. The results of the present research confirm the findings of Fatchurochim et al., (1989) that fly abundance in caged layer facilities can be determined mainly by manure moisture content through direct positive effect on fly oviposition and larval survival.

Increase in fly population in the narrow caged layer houses could be due to the increased moisture of the manure which promotes favourable condition for fly breeding. Moreover due to poor ventilation, improper manure management also increase in moisture favours for fly breeding and in contrast to this high raised poultry houses had less fly population due to good ventilation and reduced moisture due to proper manure management. 


\section{References}

Axtell, R. C., and Arends, J. J. 1990. Ecology and management of arthropods pests of poultry. Ann. Rev. Entomol., 35: 101126.

Barth, C. L. 1986. Fly control through manure management. Poult. Sci., 65: 668-674.

Fatchurochim, S., Geden C. J., and Axtel. R. C. 1989. Filth fly (Diptera) oviposition and larval development in poultry manure of various moisture levels. $J$. Entomol. Sci., 24: 224-231.

Learmount, J., Chapman. P., and Macnicoll. A. 2002. Impact of an insecticide resistance strategy for house fly (Diptera: Muscidae) control in intensive animal units in the United Kingdom. $J$. Econo. Entomol, 95 (6): 1245-1250.
Quisenberry, S. S., and Foster. D. E. 1984. Cost - benefit evaluation of house fly (Diptera: Muscidae) control in caged layer poultry house. Polut. Sci., 63: 2132-2139.

Reeb, J., and M. Milota. 1999. Moisture content by the oven-dry method for industrial testing, Oregon State University, Corvallis.

Rutz, D. A., and C. W. Pitts.1993. Pest management recommendation for poultry paipm. Web site of www. cas. psu. edu/ puplication/ poultry IPM.

Tamilam, T. V. 2008. Evaluation of Metarhizium anisopliae and Beauveria bassiana for control of house flies in poultry farms. M.V.Sc., Thesis of TANUVAS, VCRI, Namakkal.

\section{How to cite this article:}

Sathiyamoorthy, N., K. Senthilvel, N. Rani, K. Ramya and Ponnudurai, G. 2018. Association of House Fly (Musca domsestica) Intensity by Spot Card and Manure Moisture in Caged Layer Houses. Int.J.Curr.Microbiol.App.Sci. 7(02): 2566-2568. doi: https://doi.org/10.20546/ijcmas.2018.702.312 